\title{
RECURRENCIA DE UN MITO GRIEGO
}

Luis Gil, en La trasmisión del Mito dice que cuando un autor moderno se propone recrear una obra clásica debe, primero, "aprehender" la esencia del mito; sólo después puede cargarlo con las valoraciones de su entorno o de sus ideas. Tenemos ejemplo clarísimo de esto en las numerosas recurrencias del mito de Antígona que nos han dejado Brecht con su enfrentamiento a los atropellos hitlerianos, Leopoldo Marechal con las luchas por el establecimiento de una civilización cristiana donde imperaban las leyes del desierto; $y$, casi en nuestros días, Gabriela Gambaro que levanta a una "Antígona Furiosa"contra los excesos de la tiranía militar. Cocteau, Pemán, Anouilh, que muestra a una Antígona con todo el nihilismo de la Francia de posguerra.

Brunel y Chevrel mencionan la flexibilidad que debe tener el autor recurrente al recrear el mito; y hablan de los elementos extranjeros que puede introducir en la nueva obra a la que se ha llamado hipertexto,la nueva obra que puede separarse se su obra inspiradora, el hipotexto en mayor o menor grado. El autor recurrente queda en libertad, podríamos decir, de cargarla con sus valoraciones: le está permitido trasladar la acción a otro escenario o ubicarlo en otra época, Recordemos el tratamiento que hace Anouilh de Antígona y Medea: respetando el escenario clásico carga a sus hipertextos con valores totalmente distintos. $O$ Leopoldo Marechal en Antígona Vélez que, aunque distante en tiempo y espacio, mantiene los valores fundamentales de la obra griega. "Dios ha puesto en la muerte sus fronteras", dice la protagonista, defendiendo las mismas banderas de la heroína trágica.

Vamos a detenernos hoy en una obra recurrente, el hipertexto que un autor argentino hiciera del mito clásico de Orestes: Sergio De Cecco en El Reñidero. El autor argentino se ha inspirado en el mito clásico para una obra en la que muestra con toda profundidad la búsqueda de la verdad. Podemos afirmar, como en el caso del Edipo Rey de Sófocles, que el verdadero tema de la obra es el paso de la apariencia al ser. Traspone a sus protagonistas a otra sociedad pronta a desaparecer: el caudillaje porteño de comienzos del siglo XX que a semejanza del mito clásico, presenta una sociedad en quiebra: con el "colapso" sufrido después de la invasión de los dorios, que provoca en la península un real desmembramiento de la estructura social constituída por grandes palacios en torno a los cuales se desenvolvía la vida de las ciudades; ese como "espejo roto" que se produce entonces, será el fermento que desembocará, siglos más tarde en la polis griega; pero desaparece el dominio de los grandes señores para dar lugar a la "fuerza del pueblo" (que eso es la democracia: de $k \rho \alpha \tau o \zeta=$ fuerza $+\delta \eta \mu \circ \zeta=$ pueblo)

En efecto: los pelópidas son la expresión de un modo de vida que perecía en la Grecia Micénica. La familia de los Pelópidas estaba signada por una antigua maldición, por cuanto Pélope, que había matado por celos a su cochero Mirtilo, había sido maldecido por el padre de éste, el dios Hermes, que predijo una serie de calamidades sobre su descendencia: los Pelópidas nacerían con el destino predeterminado de verse sumidos en sangrientos crímenes familiares.

La familia de Pancho Morales, en la obra argentina, por otras motivaciones nace también con un destino de sangre y muerte:

\footnotetext{
${ }^{1}$ Pierre Brunel y Yves Chevrel: Compendio de Literatura Comparada. Traducción de Isabel Vericat Núfíez. Ediciones
} siglo pp., 1994 
"Al duelo lo tenemos prendido como una araña desde que venimos al mundo" (p.83).

explica Elena a Vicente al comienzo de la obra.

Orestes es el último eslabón de la cadena maldecida . Ahora este joven debe vengar la muerte que su padre Agamenón sufriera a manos de su esposa Clitemnestra quien uniendo sus viejos rencores por la muerte -pese a haber sido liberada por la intervención de Artemisa- de su hija Ifigenia a los también viejos resentimientos de Egisto por la inhumana muerte de sus hermanos en el fatídico banquete que Atreo le ofreciera a su hermano Tiestes, traman la muerte del esposo sumando así esta muerte a otra afrenta intolerable para la mentalidad griega: el conculcar el lecho conyugal.

Orestes, pues, con mayor o menor responsabilidad de sus actos según lo muestren uno u otro autor trágico, debe matar a su madre y al amante de ésta por imperio de los dioses que, según la ley de la justicia Themis la sangre derramada en una familia reclama otra sangre.

"Es una ley que las gotas de sangre derramadas en tierra reclaman una nueva sangre. La muerte llama a las Erinias para que en nombre de las primeras victimas, hagan suceder una desdicha a otra desdicha".

(Coéforas, vv.400/4).

Y permítesenos un breve paréntesis en esta consideración: Esquilo es, al decir del Dr. Eilhard Schlesinger ${ }^{2}$ el trágico cósmico: él expresa en sus obras todavía la concepción teocéntrica que ve a los dioses moviendo las acciones de los hombres; tal la mirada de los poemas homéricos. Todo el cosmos: dioses, hombres y naturaleza son parte de un gran orden cuyas leyes $\alpha \gamma p \alpha \phi o r$ rigen desde siempre. Orestes debe cumplir la venganza por orden de Loxias -Apolo- que en último término lo justificará en Las Euménides. Sófocles es, en cambio, el trágico ontológico: a él le interesa el ser - hombre; vive como en el "ónfalos"del antropocentrismo: Grecia acaba de descubrir a el hombre, a quien, desde Solón, hace responsable de sus actos. Orestes llega a Argos por imperio del dios, sí, pero también porque es él quien siente esa sed de venganza; cumplida ésta, el coro dice:

"hasta que, por fin, con el acontecimiento de hoy, recobras a duras penas la libertad" (Electra, éxodo).

Schlesinger llama a Eurípides el trágico psicológico: a él le interesa también el hombre, pero en sus reacciones internas, en sus luchas y dudas. Baste considerar el magnífico monólogo de Medea debatiéndose entre su despecho de mujer desplazada y su amor de madre ${ }^{3}$ (3). Recordemos cómo Eurípides coloca en la Electra a sus personajes en una situación casi diríamos doméstica y a Orestes cumpliendo su venganza por motivaciones puramente humanas.

\footnotetext{
${ }^{2}$ Eilhard Schlesinger: Introducción al Edipo Rey de Sófocles, U.N.L.P., La Plata, 1954.

${ }^{3}$ Eurípides: Medea, episodio V, vv. $1020-1080$.
} 
Aludíamos más arriba que la civilización micénica estaba ya en decadencia: Agamenón, jefe de la escuadra griega en su avance contra Troya, es, no obstante, un cobarde que no duda en arrebatar al mejor de sus jefes la esclava habida en botín, ni en matar a su hija por ambición o temor a sus gentes.

La obra que hoy nos ocupa, El Reñidero de Sergio De Cecco, nos muestra también a un caudillo del Palermo de comienzos del 1900 , respetado y temido, pero cuya verdaderas miserias han de ir descubriéndose a lo largo de la obra: es un paso de la apariencia al ser. Cobardía que Don Pancho Morales pone de manifiesto en el mal trato y la posesión "machista"de la mujer; en la "achicada"ante un político que detenta más poder que él, en la traición a su hijo Orestes al entregarlo él mismo a la justicia.

Porque el hilo conductor de la obra es ese ir desentrañando la realidad de esa familia respetada de Palermo. Y ese papel, fundamental, lo van cumpliendo los "raccontos", acertadísima técnica teatral.

De Cecco, que al decir de Gil "ha aprehendido"la esencia del mito, lo carga de nuevas valoraciones. Tal vez la que más salte a la vista es el exacerbado "complejo de Electra"que sufre Elena (sea dicho de paso, complejo que no sufrió la Electra clásica, como Edipo no sufrió el complejo que la psicología de nuestro siglo ha inventado).

Pasemos a establecer algunos puntos de comparación entre las obras clásicas y la recurrencia que realizara el autor argentino:

\section{El tema:}

En las obras clásicas es la venganza, como eslabón final de una antigua maldición familiar. En Esquilo, creo poder afirmar que es, en realidad, el paso de la Themis a la Dike; en Las Euménides Atenea instaura el Areópago, como forma de impartir la justicia: ya no regirá la "ley del Talión", En adelante serán los hombres quienes juzguen las acciones de los hombres, en una concepción auténticamente antropocéntrica.

El Reñidero se aparta de este tema: como ya señalamos, el tema es ese "paso de la apariencia al ser", el descubrir las miserias y cobardías de quienes ofrecen una carátula de grandes señores y son en realidad cobardes y mezquinos. Respeta la trama argumental clásica el hijo que mata a su madre y al amante- pero con algunas alternancias:

En los personaies:

- Orestes vuelve al hogar con el afán de matar al asesino de su padre desconociendo quién sea éste; cuando lo conoce, comprende que

"Soriano no era nadie, Elena.! Un pobre diablo que se calló y disimuló durante cinco años. Pancho Morales ni se desayunó, de tan delgada que fue la traición. Soriano fue la daga, pero no la voluntad de matar" (p.132).

y su amigo le ha explicado poco antes:

"Digo que Pancho Morales ... sobraba, ya no era nadie, un día u otro iba a caer, amasijao por los mismos que le habían dado su hombro 
(...) Si cayó es porque ya no tenía cómo defenderse. Era un gayo viejo y había perdido las espuelas. (p.126).

desorientado casi diríamos, grita:

"A qué? A quién? Dónde está, cómo se llama? Hace un rato creí que se llamaba Soriano... pero más luego me olvidé de él. El no es tampoco. Quizá sea Elena, quizá sea mi madre..." (p.126).

porque él, que "había nacido para matar", actúa como el instrumento mortal de la sed de venganza de su hermana.

- Elena, movida por su exagerado amor filial, se planta ante su madre no como hija rebelde, sino como rival que le disputa el amor de un hombre.

Como en la concepción clásica, es ella la que mueve a Orestes a cumplir la venganza.

- Soriano, a diferencia de Egisto, no trae ninguna causa de venganza; él es el "ladero"Don Pancho al que"solía respetar". Su situación es simplemente la de un hombre joven que se enamora de una mujer frustrada en su matrimonio

- Don Pancho Morales: es, en realidad, el personaje central. Como ya señalamos, es el personaje al que el autor va desenmascarando; arquetipo de quienes presentan una cara en sociedad, pero tienen una personalidad muy distinta y miserable. La escena del vestido de Nélida destrozado y el testimonio de la propia esposa que muestra una marcada preferencia por el hijo gestado en ausencia del marido -ya que podemos considerar que Elena fue concebida en un acto de verdadera violación- constituyen algunas de las bajezas morales en el orden familiar del protagonista.

- Nélida guarda, al igual que Clitemnestra, antiguos rencores para con su marido; pero no como en la caso clásico por filicidios anteriores, sino que es el rencor acumulado de una esposa que se sabe usada, despojada y sometida; ha encontrado en la vida a un hombre, contrafigura de su esposo

De Cecco da voz, y muy importante, al Pílades clásico; pese a que éste desempeña en Las Coéforas un papel decisivo al determinar a Orestes a cumplir el mandato del dios, ante la duda del.hijo por cometer el atroz matricidio. Pero el Vicente de El Reñidero es quien descubre la verdadera personalidad de Elena y quien descorre a Orestes muchos velos que le estaban corridos.

La Crisótemis sofóclea está dicha en la obra argentina con la vacua Teresa, puesta también acá para resaltar la fuerte personalidad de Elena.

\section{- EI CORO:}

Los autores recurrentes de las obras clásicas en general han eludido presentar un coro uniforme como el de las tragedias griegas. No obstante, ellos han "captado"el papel esencial que el coro cumplió en el teatro griego. Por eso no eluden su presencia ni sus funciones, aunque con otros recursos escénicos. Recordemos el coro de Antígona Vélez de Marechal, desmembrado en cuatro coros que, en su conjunto, llenan ese papel: hombres, mujeres, mozas y brujas. 
De Cecco hace presente también el coro griego, y lo hace en diferentes presencias: las voces de la sala contigua al velatorio con las que abre la acción, las voces del reñidero que dan comienzo al segundo acto y dos personajes principalísimos: la vieja de la primera escena, que nos anticipa la verdad hasta entonces disimulada, además de constituir el primer "golpe"en la tensión dramática:

\section{Santiago Soriano! Maldita sea tu estampa! (...) Vos enlutaste a} Pancho morales! Vos y esa perdida lo traicionaron! (P.79).

Crea además un personaje fundamental: el trapero, que cumple acá varias de las funciones del coro:

a) crea atmósfera trágica:

b) anticipa el desenlace:

"No me iré lejos. Algo me dice que no he terminado mi jornada, que hoy haberá trabajo para mi (...) Hay dias calientes y días fríos. Pero hay dias que son mucho más. Son sus dias. Los de la muerte" (p.97).

“...Sé que hoy tiene su fiesta.. La de la riña. Hoy la muerte vendrá a ver su riña y nosotros seremos sus gayos (...) y el miedo anda desnudo como un cachorro recién parido" (p.98).

c) muestra la verdadera trama de la obra:

"Yo a la noche abro el atao, saco los trapos ... y aprendo a conocerle la indole a los hombres. Taitas que por afuera eran más estiraos que cueyo e'pavo, por adentro sólo eran puro remiendo y retazo (...) Esta es la verdadera jeta de la vida, la jeta deshilachada, que si le sabés entender su chamuyo te hacés sabedora de todos los secretos de los hombres" (p.97).

\section{El desenlace:}

El Orestes clásico, en todas sus versiones, mata a su madre en un arrebato, sí, pero conciente de que ese matricidio es la venganza que reclama el uxoricidio de Clitemnestra; y esa venganza es exigida por la Justicia divina.

Las muertes provocadas por el Orestes de De Cecco son distintas: mata a Soriano enajenado por una visión -psicológica, podriamos decir- de su padre que le echa en cara su "chambonada"una vez más; y él no sabe

$$
\text { "por qué hay que pagar pa'ser un Morales?" (p.134). }
$$

La muerte de Nélida no es otro asesinato de Orestes, sino un suicidio de Nélida que, al ver perdidas todas sus ilusiones, se arroja sobre la desorientada daga de su hijo. 
En el grito aterrado de Orestes al final de la obra, podemos reconocer al Orestes esquilíneo acosado por las Erinias.

\section{Recursos dramáticos:}

Mientras que las obras clásicas tienen un desarrollo lineal, en el que el tiempo cronológico coincide con el de los personajes. De Cecco crea los "raccontos" como recurso para colocar su trama argumental "in media res": ante el hecho de la muerte del caudillo, toda la trama será un ir hacia atrás para descubrir la verdad de la mentira vivida. Algunos de los aportes de estos recursos:

1) muestran la personalidad enfermiza de Elena, con su obsesión por su padre:

"El lo era todo para mí. Mi techo, mi guía, mi sangre" (p.82).

y la indignación cuando Don Pancho entrega a la esposa un perfume que ella consideraba suyo: 'No... Era para mi ... Era para mi! ...Ella lo sabía ... Ladrona! ... Ladrona! Ladrona, ladrona, ladrona! ..." (p.94).

2) Nélida primero y Vicente después desencantan a Orestes del concepto que tenía sobre su padre: Nélida al descubrir la situación en la que la tenía sometida por su absoluto machismo; y al descubrirle que el encarcelamiento había sido debido a la traición de su padre por mezquinos intereses políticos.

Delegado: Sólo usted sabe dónde está Orestes.

Padre: Así es.

Delegado: Usted mismo tiene que entregarlo a la policía.

Padre: Pero, qué me está pidiendo?!

Delegado: Un sacrificio que va a dar la medida de su fidelidad, don Pancho (p.124).

Orestes, destruido por la revelación, confunde los planos del pasado y del presente y se desahoga con en el amigo:

Cobarde! Cobarde, Cobarde! ...Quiero verle la cara con que me ha fayuteao! Cobarde, cobarde, cobarde!! ... Me vendió como a una puta...! (p.124/25).

3) Descubren al hijo la verdadera personalidad cobarde de su padre, cuando Nélida le cuenta la verdad de la entrevista de Pancho Morales con el Delegado, Vicente ante la desolación de Orestes le descubre la ruindad moral del padre y le dice:

"Sabés cuándo empezó a quedar a acorralado? (...) Cuando te vendió. Fue una achicada, Orestes. Una achicada miserable, puerca, cobarde. Dende ese día Pancho Morales supo que la daga del más otario iba a alcanzar para matarlo. Y ése es el fin de un hombre. (p.126) 
4) Como ya lo dijéramos, introduce en la trama dos elementos desconocidos por los trágicos griegos: los complejos de Electra en Elena, y el que podríamos llamar "complejo de Yocasta"en Nélida; por cuanto de ningún modo podríamos hablar de "complejo de Edipo", ya que a Orestes

"Su enemistad, su malquerer, me llamaban mucho más que el manoseo empalagoso de ella" (p. 13)

Estamos en presencia, pues, de una obra en la que el autor recurrente ha "aprehendido"cabalmente la esencia del mito clásico, y lo ha cargado de connotaciones nuevas enriqueciendo el hilo argumental al cambiar el escenario de la acción y generando nuevas motivaciones que insidirían como causales de la maldición familiar, amén de cargarla con nuevas reacciones psicológicas de sus agonistas. Pero la riqueza inspiradora de la obra griega queda intacta, y servirá por nuevas generaciones como trasmisora de valores eternos.

Se trabajó sobre la siguiente edición de la obra:

Sergio De Cecco - Sófocles: El Reñidero - Electra, Cảntaro Editores, Buenos Aires, 1999. 